Leviathan: Interdisciplinary Journal in English

\title{
Why I Work in the \\ Field of Language \\ Variation and \\ Change
}

No. 2, 1-12

(C) The Journal Editors 2018

Reprints and permissions: https://tidsskrift.dk/lev

DOI: $10.7146 /$ lev.v0i2.104686

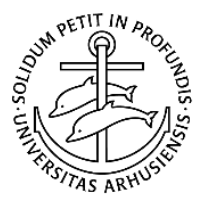

Michaela Hejná

\begin{abstract}
This perspective introduces the reader to what it is that a linguist working within the field of language variation and change does. I first outline what the goals of the field are. Next, I provide examples from my own work that illustrate what a researcher in my field may investigate and how. I also discuss what a teacher in my field can get to teach and why interacting with the students is, in my view at least, essential. We finish with a brief comment on whether and how the world can benefit from the insights of the field.
\end{abstract}

Keywords: linguists; language variation and change; historical linguistics; phonetics; phonology

Corresponding author: Michaela Hejná (misa.hejna@cc.au.dk)

Department of English, Aarhus University 
Oh, you're a linguist. So how many languages do you speak?

There is a common belief that linguists busy themselves with learning a high number of languages. When I get asked how many languages I speak once people realise I'm a linguist, I can't help sighing a little, deep inside. Other linguists may be compelled to follow up on their inner sighs with online log entries (see for example “The linguists strike back” by Liberman 2016). Or you may decide it’s time to contribute to Leviathan with a paper that explains what you do. As a linguist, what I actually do is conduct research and teach courses related to language variation and change and, if there is anything I would regret not having done before dying, it would be not sharing with our students what doing research in my field can be about, and why this research makes my heart beat.

\section{Where do I begin?}

I have always been fascinated with variation: where does it come from, why does it exist? This curiosity has never left me, but it has over the years become more concentrated on language and speech. As Pinker explains, a linguist is "[a] scholar who studies how languages work. [This d]oes not refer to a person who speaks many languages.” (Pinker 1994, 478) To me, it was the fact that we can speak about languages (yes, in the plural) that kept me asking some of the following questions. Why do the languages of the world differ? And how come they don't always differ (that much)? Why do dialects exist? Why do different individuals speak differently? Are there limits to language variation? A whole whirlwind of questions emerged. Perhaps because of my strong synaesthesia, which makes sounds of languages full of colours for me, I have been particularly drawn to variation in the domain of sounds that we can find in languages. (That makes me a phonetician and a phonologist.) Many years later, I am very happy to report that I can spend most of my life doing research that enables me to move a little bit closer to answering the never-ending questions related to language variation and change that all the fascination started with. (Which places me within the field of language variation and change.)

So what does a researcher in the field of language variation and change do exactly? What does a teacher in this field teach? Can the world benefit from the insights of the field of language variation and change? I can only give you my own viewpoints to answer these questions, and that's what I do in the rest of this paper.

\section{What does a researcher in the field of language variation and change do?}

If you want a very concrete answer to this question, you should bear in mind that you will get very different answers depending on whom you ask. Generally, however, there are the so-called five problems in the theory of language change (see Weinreich et al. 1968), to which language variation is indispensable since language change always implies language variation.

The first problem is the constraints problem: what conditions language variation and change and why? For example, the main difference between some accents is that some have an $/ \mathrm{r}$ / in words like car and others don't, and this difference can be predicted by aspects such as the position of the affected / $\mathrm{r} /$ within the word. You may know many speakers who don’t pronounce their /r/'s in words like car, but would these speakers 
also omit the $/ r$ / in words like rack, where the $/ r$ / is word-initial? We can see that there must be some constraints on where people do not pronounce /r/'s in the relevant English accents. The second problem is called the transition problem: how does it happen that generation $\mathrm{X}$ shows linguistic differences when compared to generation $Y$ ? To take our $/ \mathrm{r}$ / example again, how does it happen that generation $\mathrm{X}$ pronounces $/ \mathrm{r} /$ in a word like car and generation $\mathrm{Y}$ does not? And how does linguistic innovation, such as $/ \mathrm{r} /$-loss, spread throughout a community? (It's highly unlikely that everyone in a community suddenly stops pronouncing their/r/s in words like car.) The third problem is the embedding problem: how is a specific innovation embedded in the linguistic structure and the social structure of the relevant community? For instance, are some social classes more likely than others to lose /r/'s in their cars? The fourth problem is the evaluation problem: how do members of a speaking community evaluate a linguistic feature? Is /r/-loss stigmatised? Is it seen as prestigious? Neither? Perhaps both? Finally, we get to the fifth and the most challenging problem, the so-called actuation problem. Why does language change happen where and when it does and not in a different place and at a different time? (And how many individuals need to show the innovative linguistic feature for us to label it change in the first place?) Why do we start losing /r/'s only in some English accents and why is it in these specific accents that the loss happens? The last problem is indeed the toughest one, so much so that some linguists have suggested we will never be able to tackle it satisfactorily (see Stevens \& Harrington 2014 for an overview). However, if we adopt such a stance, then the only thing we will ever be able to predict is that we will never get anywhere closer to the heart of the actuation problem. Whilst in theory we can separate these five problems, in practice we find that they overlap. In my own research, I am most interested in the constraints and the actuation problems.

Take a phenomenon known as breathiness, a voice quality during which more air escapes from our vocal tract, which results in voices that sound softer to us. Are there any social and/or biological constraints on how speakers employ this voice quality? If it is the case that females are generally breathier than males (e.g. Henton \& Bladon 1985; Simpson 2009), why should that be so? Are different degrees of breathiness associated with attraction in any way (e.g. Hall 1995; Liu \& Xu 2011)? What aspects of attraction? And why should female breathy voice be associated with the degree of attraction in the eyes (or ears) of heterosexual male listeners? Can this have anything to do with the fact that females have been reported to produce breathier voices during their ovulation and that their voices are perceived as more attractive during this period (Pipitone \& Gallup 2008; Raj et al. 2008)? Could there be certain hormonal changes that also affect the laryngeal structures in such a way that may lead to higher degrees of breathiness as a result? Those are some of the questions I have just started looking into on my own as well as with the help of some of my students (see e.g. Laura Bisbo’s contribution in this volume of Leviathan; or take a look at Hejná 2018).

The example of breathiness I've given you above may however not be of interest to all linguists interested in sounds. This is because sounds can be linked to different types of meaning and not everyone is interested in all types of meanings we can think of. For this reason, I'm also going to give you an example which is directly linked, or at least more directly linked, to lexical meaning and linguistic structure. But before I can do that, what do I mean by lexical meaning and linguistic structure? Let me try and explain. If I say When I go to the forest at the weekend, I make sure to say hi to my favourite trees. in a breathier, softer voice than usual, the individual words will mean exactly the same thing, i.e. the words $h i$ and trees won't suddenly refer 
to bumblebees, kingfishers, or cucumbers if I produce these words with more breathiness (which does actually happen in some languages - very cool). So the lexical meaning of these words is not affected by breathiness. That doesn't mean that breathiness doesn't signal anything here - it just doesn't change what the words refer to. And this is what lexical meaning is about. If instead of changing the voice quality, on the other hand, we take a word like $h i$ and we replace the $/ \mathrm{h} / \mathrm{with}$ a $/ \mathrm{b} /$ or an $/ \mathrm{f} /$, these substitutions will result in rather different words (=lexical meanings). Indeed, hi (/haI/), bye (/bai/]), and fie (/fai/) are associated with rather different lexical meanings (and I don't think my favourite trees would be impressed with me saying fie to them on a regular basis). Because this is so, we can say there's a contrast between /h/, /b/, and /f/ in English. We could also say that English /h/, /b/, and /f/ are contrastive.

I would now like to give you an example of a phenomenon that illustrates variation linked to lexical meaning from my own research. One of the phenomena I fell in love with is pre-aspiration. If I simplify things a little, I would say that pre-aspiration is a sound like /h/ that can be produced by speakers between vowels and consonants such as $p, t, k, f, t h, s, s h(/ p, t, k, f, \theta, s, f /)$, so that words like mass and pat are pronounced as $m a^{\mathbf{h}} s s$ and $p a^{\mathbf{h}} t$ (e.g. in Welsh English, this could be phonetically transcribed as [ma $\left.{ }^{\mathrm{h}} \mathrm{s}\right]$ and $\left[\mathrm{p}^{\mathrm{h}^{\mathrm{h}}} \mathrm{a}^{\mathrm{h}} \mathrm{t}^{\mathrm{s}}\right]$ ). When I first encountered pre-aspiration myself, I had no idea what it was and so I started digging into what other linguists had to say about it. Not only has it been claimed that pre-aspiration is rare in the world's languages, it has also been claimed that it’s rarely contrastive (see Hejná 2015 or Hejná 2016 if you want to know what I think of that). What does that mean? The claim is related to whether pre-aspiration contributes, in any way, to distinguish /p, t, k/ from /b, d, g/, for example ("voiceless” and “voiced” stop consonants). For instance, if preaspiration contributed to this "voicing” contrast, a word like pat would be less easily identifiable as such by the listener if pre-aspiration was missing. As a result, the word would more likely be identified as pad instead. One of the reasons put forward as to why pre-aspiration is so rare is that it doesn't contribute to contrasts like this one particularly well. But along with other linguists, I have nevertheless found that pre-aspiration can function as a robust correlate of the contrast between /p, t, k/ and /b, d, g/ (Hejná 2016) and as a perceptual cue to the contrast as well, all else being equal (Hejná \& Kimper, Submitted). In other words, pre-aspiration is contrastive in more languages than previously reported, although we still need to answer many questions in this avenue of research.

And it turns out that pre-aspiration can be subject not just to a number of structural (language internal) constraints, e.g. that of the "voicelessness" of stops (/p, t, k/ versus /b, d, g/). It can also be affected by social (language external) constraints, including for example the home language of the pre-aspirators in question, as reported for Bethesda Welsh (e.g. Morris \& Hejná, in press). But we don’t know just how many constraints on pre-aspiration there can be and to what extent these apply in a range of pre-aspirating languages. Without establishing these facts first, we cannot hope to say anything conclusive about why a language or a dialect develops pre-aspiration when it does (and even then, we still have a lot of other explanatory work to do).

Sometimes you come across phenomena unrelated to your specific research questions that make you way too curious, and you must find out more about them to understand what they are and why they exist. Thus came about my work on glottal squeaks. Yes, I know, the way they sound and the way they look on spectrograms and in soundwaves are just as cute as their name suggests. If you don't believe me, just look at 
the waveform and the spectrogram below, where I highlighted a little wiggle (top) and a blob of darkness (bottom) so you know what a glottal squeak looks like.

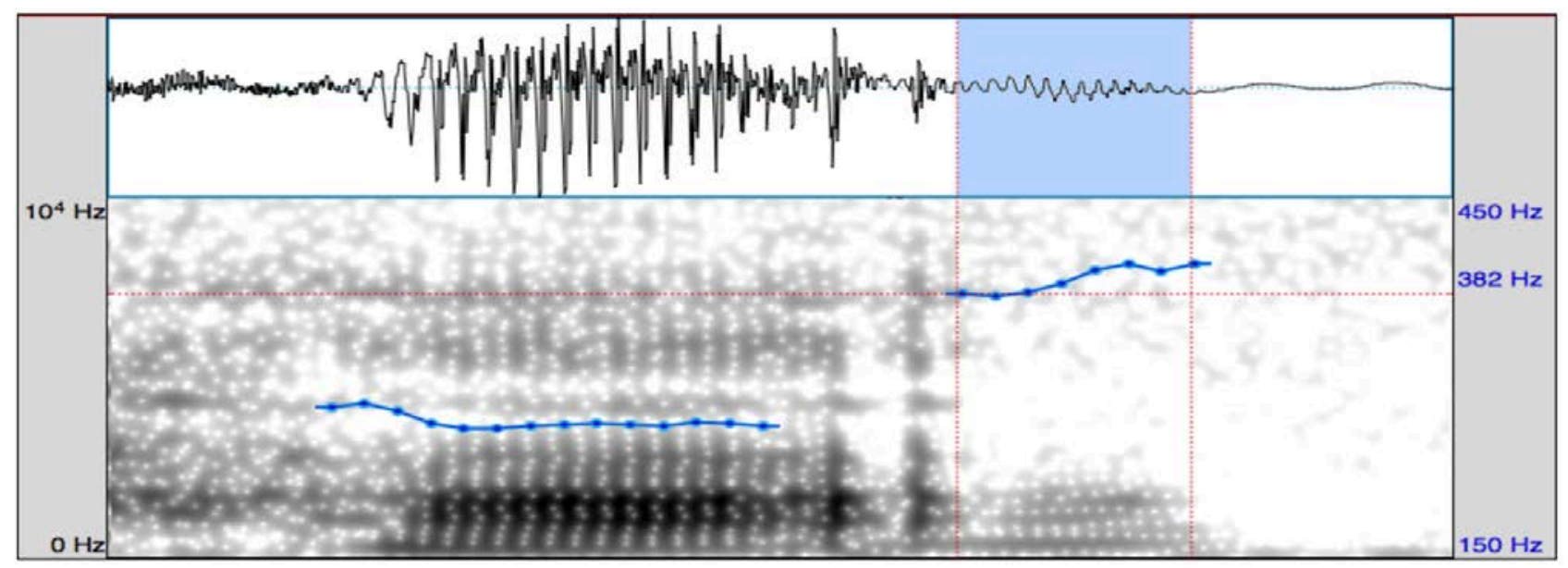

Figure 1. Waveform and spectrogram showing the word hat [ha?]; the highlighted portion displays a glottal squeak.

To my dismay, I had not seen the phenomenon commented on, let alone explained, in any of the literature I was familiar with. I may have jumped a little when I finally found a paper that acknowledged their existence and gave them a name. But the question remained: what and why are glottal squeaks? To start answering the question, I’ve looked into what conditions their occurrence in speech, which brings us at least a little bit closer to the what and why (Females seem to be the predominant squeakers.). If interested, you'll have to read Hejná, Palo \& Moisik (2016). You may be disappointed though to learn that we're still not sure what exactly these glottal creatures are and how and why they happen. But then that's one unavoidable face of research for us.

The field of language variation and change, as the name of the field suggests, therefore concerns itself with how and why language varies and how and why language change takes place. This means that the field of historical linguistics is part of the field of language variation and change (since historical linguistics focuses primarily, but not only, on language change). But every now and then I face a certain degree of puzzlement when people discover that I am interested in historical linguistics in my research and teaching. I suspect this is because acoustic, articulatory, and perceptual analyses are not usually associated with historical linguistics by non-linguists. So...

\section{So... if you're not working with mediaeval manuscripts, you can't be a historical linguist, right?}

Not right. Let's say that I want to answer how certain types of sound change are motivated, say a change from $/ \mathrm{k} /$ to $/ \mathrm{t} \mathrm{f}$, which took place in Old English (resulting in Present-Day English church) but not in other languages such as Old Norse (resulting in Present-Day English kirk, present in dialects of English in Scotland and the north of England, which was borrowed from Scandinavian, where the change from $/ \mathrm{k} / \rightarrow / \mathrm{t} /$ did not take place; see Minkova 2014, 84-5, and think of Danish kirke). How 
and why does a change like this happen? Unfortunately for us, this sound change happened so long ago that there are no speakers available to us now who were also alive when the change began. It is rather frustrating that the only thing we can observe directly is the result of this sound change. This means that we can only speculate about whether this change happened due to physiological biases, perceptual biases, or a mixture of the two, for instance.

But can we only speculate? Not if we espouse the Uniformitarian Principle, according to which the general principles that govern sound change today should also apply in other centuries. We should be able to explain the change from $/ \mathrm{k} / \rightarrow / \mathrm{t} /$ (palatalisation) that happened in Old English in a way similar to how we explain the same change in later stages of English (Present-Day English got you vs gotcha, don't you vs dontcha) as well as in other languages (for more information, read Ohala (1994) and the references therein). This is comforting, because unless we magically gain the powers to resurrect speakers long gone (including their vocal tract tissue), working only with manuscripts will provide us with limited answers. On the other hand, that it is possible to get far using manuscripts has been demonstrated admirably by Minkova (2004, section 4.2 on the evidence of the glottal stop in Old English).

The Uniformitarian Principle applies to language change in general. For example, a fairly recent change known as s-retraction involves pronouncing /st./ more like / ftu/ in some English accents, so that a word like street may sound like shtreet. How does this happen? One theory holds that it is something to do with the pronunciation of the $/ \mathrm{r}$ / sound that affects the pronunciation of the antecedent /s/ sound (see Stevens \& Harrington 2016 for an overview). But if that were so, why don't we observe s-retraction also in words such as scream and spree? Or do we? Luckily for us, there are plenty of English speakers around who can be (lovingly) taken to the lab for articulatory experiments so that we establish whether some types of $/ \mathrm{r} /$ sounds are more likely to be linked with /s/ changing to / $/$ than others, and whether this happens differently in the vicinity of /t/ as opposed to /p/ and /k/. The results should then also inform the processes involved in s-retraction taking place in other s-retracting languages and varieties, such as Standard German and some regional varieties of Italian (Stevens \& Harrington 2016; if this intrigues you, Stevens \& Harrington 2016 present an excellent overview, and Baker et al. 2011 is also a very important contribution).

An example from my own research is related to a phenomenon called aspiration dissimilation, whereby consonants with an aspirate feature (a puff of voiceless friction, like that associated with /h/) lose this aspirate feature in the vicinity of another consonant with an aspirate feature. If we wanted to think of an example from English, we would have to make one up. Take a word like packer ([p ${ }^{\mathrm{h}} \mathrm{ak}^{\mathrm{h}}$ )] in a Welsh English accent), which has $/ \mathrm{p} /$ and $/ \mathrm{k} /$, both of which are associated with a puff of glottal friction (aspiration). Now, if aspiration dissimilation applied, instead of what we identify as packer, we would get what would sound either like backer ([pak $\left.\left.{ }^{\mathrm{h}} \mathrm{\partial}\right]\right)$ or pagger ([p $\left.\left.\mathrm{p}^{\mathrm{h}} \mathrm{ak} \mathrm{p}\right]\right)$ so either the /p/ of the packer, or the $/ \mathrm{k} /$ of the packer would lose its puff of friction. But nothing of the sort would 
happen in words such as lacquer or candy, where we only have one consonant with an aspirate feature (There's no puff of friction associated with /l/ or /n/ in English.).

Believe it or not, aspiration dissimilation is another puzzling creature. It is rather frustrating that the main knowledge about how it happens is related to evidence from Sanskrit and Ancient Greek (try googling Grassmann's Law), neither of which is spoken today (and resurrecting speakers from the relevant period is, again, beyond my technical expertise). Does this mean that we can only speculate? Again, and happily, it does not. Very conveniently, one of my collaborators and I actually found aspiration dissimilation in English spoken in Aberystwyth, mid Wales - right now, today! Yes, I know, it's awesome. But it wasn't the traditional description of aspiration dissimilation that we were finding in Aberystwyth English: instead of losing the aspirate feature altogether, we have found that it gets shortened. Could this be a historical precursor to the categorical deletion of the aspirate feature? Is it less rare in the languages of the world than is generally believed? The gradient pattern has also been reported in Halh Mongolian, although the report did not provide us with the amount of detail we had hoped for. And so we leapt at the opportunity to record Halh Mongolian speakers in Paris (that's where my collaborator was based at the time; sadly, we didn't get to go to Mongolia...) to find out whether we get the gradient type of aspiration dissimilation here too.

And we do.

But this is where things become truly exciting: other Mongolian languages show the complete aspiration dissimilation, which leaves us wondering whether we are on the right track in thinking that gradient aspiration dissimilation is the first historical step on the path to the categorical aspiration dissimilation. If you want to know more, check out Jatteau \& Hejná (2016) and watch the space for Jatteau \& Hejná (in prep), or simply get a sneaky peak in Jatteau \& Hejná (2017). We are nowhere near having satisfactory answers, but the important lesson here is that analysing sound patterns in the $21^{\text {st }}$ century can shed light on the processes we observe in the past as well.

So there are many reasons why I prefer to work directly with human beings, instead of with texts surviving from human beings of a bygone age, and working with language as produced in the $20^{\text {th }}$ or the $21^{\text {st }}$ centuries doesn't make my research any less historical than working with a set of manuscripts from the $16^{\text {th }}$ or the $17^{\text {th }}$ centuries. Sure, some aspects of the methodology may be rather different due to the type of evidence at our disposal for different historical periods, but the questions remain the same. To me, historical linguistics is part of the field of language variation and change that cannot be amputated from it without jeopardising the patient.

(Just in case I left you wondering, there's much to be liked about mediaeval manuscripts by linguists interested in language variation and change, and I am no exception in this respect.) 


\section{What does a teacher in the field of language variation and change teach?}

I started working at the Department of English at Aarhus University (and in Denmark) in January 2017. In my current position at the department, I regularly teach one half of "English Linguistics 2”, which deals with the "History and the Development of the English Language" (aka HEL, but the naturally biased me would like to believe it's a rather divine type of HEL). I also teach "English Linguistics 3: English in its Social Contexts”, which is a course on English sociolinguistics. There are other courses I am involved in (e.g. "Disciplinary Perspectives”), in which I get to teach about phonetics/phonology and/or language variation and change. There's a number of reasons why I find teaching on these courses very fulfilling.

Language variation and change is something that all of us experience, although some more consciously than others. This means I get to interact with a wide range of different individuals, who bring in myriads of ideas about topics that can be very refreshing. Imagine doing a job in which you get a chance to have your own worldview expanded on a regular basis. Imagine having a job in which you can support someone's enthusiasm about a certain research topic, which may lead to them investigating that topic more rigorously and thus contribute to the knowledge of the field. And it really doesn't matter whether the contribution is only very small. This creates what I like to think of as a loop of enthusiasm. You hope that your own enthusiasm will make the students (at least a little bit more) enthusiastic. When that happens, the enthusiasm comes back, knocking on your office door - admittedly with a force of variable intensity.

To give you a concrete example of an enthusiasm loop, it wasn’t until I started supervising BA dissertations at Newcastle University that I became more interested in how sex and gender interact with language variation and change. Language variation induced by various aspects of gender identity was a very popular topic with my former Newcastle students. The students often came to me with ideas about aspects of gender I knew very little about. As a teacher, I had two options: either I could make the students focus on something I knew more about or I could do my best to help them out with their research question and methodology. I chose the latter and did my best to link their smaller questions with the bigger questions in the field. Two years later, I am involved in a research project looking into a possible endocrine basis for gender effects in linguistic variation, together with my colleagues based at Newcastle University (see Hejná et al. 2017). Prior to 2015, I would not have foreseen that I would end up giving a Christmas course titled "Language and Gender: Conducting a Case Study” at Charles University in 2017. Had it not been for my curious students (and colleagues), my own curiosity about this topic might not have made it beyond its seed stage. And so, sometimes at least, students and I get into this creative loop.

But if inspiration lies at every turn, you can hardly get the opportunity to explore all the questions that pique your interest. As a result, I appreciate it very much when some of our students decide to follow up on some of the questions I don't have time to look into myself, as part of their 
final essay or their BA project. Although this does not happen particularly frequently, I have been very lucky in that some of the BA projects and even second-year course projects that I have supervised made it to conference talks (Bramley et al. 2015; Hejná et al. 2017) and a publication in the proceedings of the International Congress of Phonetic Sciences (Hejná \& Scanlon 2015). These achievements have made my heart glow and they make me feel grateful that I could be part of it all, in my own way.

Because of my appreciation of and need for loops of enthusiasm, I initiated and - together with Anna Jespersen - became the coordinator of a new research group at Aarhus University, called Sounds of Language and Speech (aka Phon-phon for phun; find out more about our group here https://soundsoflanguageandspeech.wordpress.com/.). The research group presents a very informal and friendly environment for anyone who's curious about what phoneticians and phonologists occupy themselves with and why. It doesn't matter whether you are a curious BA student or a postgraduate student, a postdoc or a lecturer. And it doesn't matter whether you study at the Department of English either. You can be as active as you please or as passive as you please. The group exists so that loops of enthusiasm and other essential forms of support happen. This, to me, is an indispensable part of what I do.

\section{How does the world benefit from the insights of language variation and change?}

Finally, if we disregard for a moment the sheer wish to make a bit more sense of our world(s), you may ask why someone would bother with language variation and change at all. Who gets to benefit? The most well-known examples are related to invidious cases of linguistic discrimination in education and at court, but also in other contexts (e.g. films, commercials and advertisements), presented as such to the world by Baugh (2007), Labov (1966), and Lippi-Green (2012), to name but a few. But that's not where applied uses of the field stop. Some of the areas that come to mind are those of education and forensics at a more general level (i.e., not limited to issues of social inequality), textto-speech and speech-to-text applications, and clinical uses. For a very interesting example within a medical context, see Pichler \& Hessen (2016), who find that different pronunciations of I don't know (contrast this for instance with I dunno.) may cue rather different messages on part of a patient who is communicating with their doctor.

This wide range of uses of scholarship on language variation and change shouldn't surprise us - as I mentioned above, language variation is present in the lives of all of us.

\section{In the end Is Our beginning}

I have attempted here to clarify what it is that I do and why, and why I am grateful to have the job that I have. But there are as many answers to the questions discussed in my contribution as there are 
linguists. So go ahead and be inquisitive; enjoy heading curiously onwards; and know that diversity is good, healthy, and normal.

\section{Acknowledgements}

I am grateful to Anna Jespersen and Jens Kjeldgaard-Christiansen, who very kindly and patiently provided comments to make this text more reader-friendly. I am of course to blame for any leftovers of textual unfriendliness. 


\section{References}

Baugh, J. 2007. “Attitudes towards variation and ear-witness testimony: linguistic profiling and voice discrimination in the quest for fair housing and fair lending”. In: Sociolinguistic Variation: Theory, Methods, and Applications. Edited by R. Bayley and C. Lucas, 338-348. Cambridge: CUP.

Baker, A.; Archangeli, D.; Mielke, J. 2011. "Variability in American English s-retraction suggests a solution to the actuation problem”. Language Variation and Change 23, 3: 347-374.

Bramley, L.; Maher, S.; Paterson, S.; Hejná, M. 2015. "Variability in British English /t/: preliminary study”. Paper presented at Manchester Forum in Linguistics, Manchester, UK. Available at https://misprdlina.files.wordpress.com/2013/06/variation-in-british-english-t.pdf.

Hall, K. 1995. "Lip service on fantasy lines”. In: Gender Articulated: Language and the Socially Constructed Self. Edited by K. Hall and M. Bucholtz, 183-226. New York: Routledge.

Hejná, M. 2015. Pre-aspiration in Welsh English: A Case Study of Aberystwyth. PhD thesis, University of Manchester.

Hejná, M. 2016. “Multiplicity of the acoustic correlates of the fortis-lenis contrast: plosives in Aberystwyth English”. Interspeech 2016, San Francisco: 3147-3151.

Hejná, M. 2018. “Hormonal effects on language and speech”. Talk given at Sounds of Language and Speech. Slides available at https://misprdlina.files.wordpress.com/2018/02/phon2018.pdf.

Hejná, M.; Scanlon, J. 2015. “New laryngeal allophony in Manchester English”. 18 $8^{\text {th }}$ International Congress of Phonetic Sciences, Glasgow.

Hejná, M.; Palo, P.; Moisik, S. 2016. “Glottal squeaks in CV sequences”. Interspeech 2016, San Francisco: 1136-40.

Hejná, M.; Cochrane, C.; Ackerman, L.; Wallenberg, J. 2017. “An endocrine basis for gender effects in linguistic variation”. Poster presented at the $4^{\text {th }}$ International Workshop on Sound Change, Edinburgh, UK. Available at https://misprdlina.files.wordpress.com/2013/06/201704wsc_edinburgh1.pdf.

Hejná, M.; Kimper, W. Submitted. "Pre-closure laryngeal properties as cues to the fortis-lenis plosive contrast in British English”. In: Yearbook of the Poznan' Linguistic Meeting 2017.

Henton, C.G.; Bladon, R.A.W. 1985. "Breathiness in normal female speech: inefficiency versus desirability”. Language \& Communication 5, 3: 221-227.

Jatteau, A.; Hejná, M. In prep. "How does aspiration dissimilation come about? Evidence from Halh Mongolian”. Papers in Historical Phonology 2.

Jatteau, A.; Hejná, M. 2017. "Gradient dissimilation in Mongolian: implications for diachrony”. Paper presented at The Third Edinburgh Symposium on Historical Phonology, Edinburgh, UK. Available at https://misprdlina.files.wordpress.com/2017/12/jatteau-hejna-esph-slides.pdf.

Jatteau, A.; Hejná, M. 2016. “Dissimilation can be gradient: evidence from Aberystwyth English”. Papers in Historical Phonology 1: 359-86.

Labov, W. 1966. "Some sources of reading problems for Negro speakers of non-standard English”. In: New Directions in Elementary English. Edited by A. Frazier, 140-167. Champaign, IL: National Council for Teachers of English.

Liberman, M. 2016. “The linguists strike back”. Language Log, http://languagelog.ldc.upenn.edu/nll/?p=23394 (Last accessed in March $7^{\text {th }}$, 2018).

Lippi-Green, R. 2012. English with an Accent: Language, Ideology, and Discrimination in the United States. London/New York: Routledge. 
Liu, X.; Xu, Y. 2011. "What makes a female voice attractive?”. $17^{\text {th }}$ International Congress of Phonetic Sciences, Hong Kong: 1274-1277.

Minkova, D. 2004. Alliteration and Sound Change in Early English. Cambridge: CUP.

Minkova, D. 2014. A Historical Phonology of English. Edinburgh: Edinburgh University Press.

Morris, J.; Hejná, M. In press. "Pre-aspiration in Bethesda Welsh: a sociophonetic analysis”. Journal of the International Phonetic Association.

Ohala, J.J. 1994. "Hierarchies of environments for sound variation; plus implications for 'neutral' vowels in vowel harmony”. Acta Linguistica Hafniensia 27: 371-382.

Pichler, H.; Hesson, A. 2016. "Discourse-pragmatic variation across situations, varieties, ages: I don't know in sociolinguistic and medical interviews”. Language \& Communication 49: 1-18.

Pinker, S. 1994. The Language Instinct. How the Mind Creates Language. New York: HarperPerennial.

Pipitone, R.N.; Gallup, G.G. 2008. "Women's voice attractiveness varies across the menstrual cycle”. Evolution \& Human Behavior 29: 268-274.

Raj, A.; Gupta, B.; Chowdhury, A.; Chadha, S. 2008. "A study of voice changes in various phases of menstrual cycle and in postmenopausal women”. Journal of Voice 24, 3: 363-368.

Simpson, A. 2009. “Phonetic differences between male and female speech”. Language \& Linguistics Compass 3, 2: 621-640.

Stevens, M.; Harrington, J. 2014. “The individual and the actuation of sound change”. Loquens 1, 1: $\mathrm{e} 003$.

Stevens, M.; Harrington, J. 2016. “The phonetic origins of /s/-retraction: acoustic and perceptual evidence from Australian English”. Journal of Phonetics 58: 118-134.

Weinreich, U.; Labov, W.; Herzog, M.I. 1968. "Empirical foundations for a theory of language change”. In: Directions for Historical Linguistics: A Symposium. Edited by W.P. Lehmann and Y. Malkiel, 97-195. Austin: University of Texas Press. 